Andrew BAILEY

Department of Art History, York University

Toronto, Canada

andrewrb@yorku.ca

\title{
AUTHORITY OF THE WORM: EXAMINING PARASITISM WITHIN INSIDE AND UPSTREAM COLOUR
}

\begin{abstract}
Recommended Citation: Bailey, Andrew. "Authority of the Worm: Examining Parasitism Within Inside and Upstream Colour." Metacritic Journal for $\begin{array}{lllll}\text { Comparative Studies } & \text { and } & \text { Theory } & \text { (2018): }\end{array}$ https://doi.org/10.24193/mjcst.2018.6.03
\end{abstract}

\begin{abstract}
Within science fiction the parasite has long provided a way to engage with bodily fears, however in recent years, our perceived relationship with these kinds of organisms have become increasingly cognitive and existential. Parasites that influence their host's thoughts and behaviour such as the Cordyceps fungus have become favourite topics for nature documentaries and science podcasts. This familiarity has given rise to narratives that utilize the parasite as an allegory of control, authority, and free will. Two works that embrace this are Playdead's video game Inside (2016) and Shaun Carruth's film Upstream Colour (2015), both featuring parasites that are systematically gestated within livestock to be later used in the mental domination of humans. Using a comparative methodology, this paper will examine the significance of animal farming and parasitic infection within both of these works as well as explore their metaphorical relationships with concepts of anthropocentrism, industrialization, hegemony, and dystopia.
\end{abstract}

Keywords: parasitism, control, free will, science fiction, dystopia, non-human 


\section{Parasitic History}

Within the genre of science fiction film parasites have more often than not functioned as representations of body horror and the grotesque. Canonical examples from the 70 s and 8os such as Ridley Scott's Alien (1979), John Carpenter's The Thing (1982), and David Cronenberg's Shivers (1975) all use a variety of parasitic organisms to construct allegories of embodied, biological fear. ${ }^{1}$ During their time these films reflected the then growing societal concerns around bodily issues such as the rise of genetic engineering and the looming AIDS crisis. Within this context, parasites are used within these films to break down the integrity of the infected bodies depicted on screen and provoke a reaction of horrific repulsion within audiences. In an essay on the cross-sections between science fiction and horror, Istvan Csicsery-Ronay categorizes these kinds of parasitic infections as a of grotesque inversion of the sublime that "disturbs the sense of rational, natural categorization" (71). Similarly, in a comparative study of Scott and Cronenberg's body horror films, Kelly Hurley categorizes these fictionalized parasitic infections as ones that dismantle the perceived boundaries of the human form and identity (205).

Due to the popularity of these early films, parasites have become an increasingly common trope within the genres of science fiction and horror. Relatively more recent films such as Robert Rodriguez's The Faculty (1998), James Gunn's Slither (2006), and Ridley Scott's Prometheus (2012) all continue on with this same focus on the violation, transformation, and destruction of the human body. Additionally, outside of the realms of science fiction and horror, parasites have also become an increasingly frequent topic for natural science media such as podcasts, television programs, and documentary films. In their book on environmental horror, Robin Murray and Joseph Heumann examine this shift within science media to sensationalize the parasite through the example of Animal Planet's Monsters Inside Me (2009-2017) television documentary series (125). Here Murray and Heumann point out that while many biologists would agree that parasites play a necessary part of our biosphere, popular science media

\footnotetext{
${ }^{1}$ For a broader overview of the science fiction genre that goes beyond body horror, see Lathham.
} 
often works to present parasites as shadowy monsters that consume their hosts from the inside out.

Considering this history of parasitic representation within horror, science fiction, and popular science it may seem as though the parasite has and will always be a concept tied to the repulsive, anatomical invasion of the body. However, if we examine the distant etymology of the word, we will begin to see the origins of the parasite as a slightly ambiguous social construct in addition to its more recent categorization as a biological organism. Originally, the parasite was defined within fifth century BCE Greece as a religious figure who received food in exchange their services in temples and at festivals. Later the term also began to applied to non-religious figures who would attempt to earn a seat at the dinner tables of the rich by telling stories and performing dramas. Remarking on this history within the context of current political discourse, Anna Watkins Fisher states that:

...the parasite thus performs a social short game: it agrees to play by the rules of its host in exchange for having its immediate needs met. It performs its consent, and in return it eats, signing in its acquiescence a tacit contract with its host (393).

Picking up on this same etymology of the parasite as a social figure, Anders Gullestad points out the conflicting ways in which the term has been pejoratively used to dehumanize people throughout history. One of the most concise examples of this conflict that he demonstrates is a comparison between Irish Socialist James Connolly who proclaimed that the wealthy capitalist feeds off of the working class, and Russian-American writer Ayn Rand who applied similarly parasitic descriptions to the homeless, the poor, and those trying to reform society in order to help them ${ }^{2}$. Gullestad concludes his comparison between Connolly and Rand by stating:

2 For additional criticism of Ayn Rand's perspectives on social parasitism, see Burns, especially 73-113. 
...the only thing the two positions have in common is the view that the parasiteno matter if in animal or human shape-is a useless creature whose only contribution is of a negative kind, draining the health of its host organism. The fact that the opposite poles of the political spectrum are here in complete agreement says something about how common this extremely low opinion is.

Although there is a strong variance between how the parasite was originally defined as kind of performer to its current socio-political usage as an insult for someone perceived to be unproductive or useless, they are connected across time through their connections to labour, payment, and resources. In this context the parasite is less connected to the human body through biological invasion as it is within science fiction and parasitology, but instead through hospitality, consumption, and performative labour3. However, rather than working to keep these two definitions distinct from one another, what could be gained from considering the parasite as both a biological and social entity? If the body horror that was spawned during the 70 and 80 s used the parasite to reflect societal fears surrounding biotechnology and disease, how can contemporary science fiction use it to help us identify and examine current issues such as the environment, the non-human, and networks within our increasingly digitized and dystopic world?

The aim of this paper is to discuss some potential answers to the questions posed above by analyzing two instances where the parasite has been used simultaneously as a social mechanism, as well as an infectious organism within science fiction narrative. The two pieces of media selected for this study are Shane Curruth's experimental film Upstream Color (2013), and Playdead's puzzle platform video game INSIDE (2016). Both of these titles are considered to be independent, artistically motivated productions within each of their respective industries, and can allow for productive comparison within the context of the parasite for a number of reasons.

The first and most obvious reason to compare these two titles through the lens of parasitism is because both include the existence of an invasive worm that

3 For more general information on performative labour, see Bryman 103-105. 
forces their infected host to become extremely susceptible to influence and manipulation. Within Upstream Color this mind control parasite is used to instigate a strange, looping cycle that begins with kidnapping and theft and ends in a surreal form of industrial animal farming. INSIDE also prominently features a similar kind of worm that is agriculturally grown and harvested before being used to infect people and turn them into mindless labourers. This reliance on industrial and agricultural settings is another reason why these two titles make for allow for easy comparison. As the body horror that was outlined above reflects the biological fears of the 8os, these parasitic farms in turn reflect more current tensions surrounding humanity attempts to control each other and the environment around them. Within Upstream Color, the worms and animal farm work together to subtly construct a systemic network that reflects the current theoretical discourse on the relationships between human and non-human actors. Alternatively, INSIDE depicts a broken, apocalyptic world where the worm farms are an initial stage in a vast hive mind of parasites and infected labourers.

To answer the questions posed above in regard to the parasite as an allegory for contemporary fears surrounding the environment and information networks, this paper will heavily rely on Donna Haraway's recent eco-assemblage theories and Wendy Hui Kyong Chun's examination of user control. Haraway's environmental metaphors will be useful in helping to construct a new hybrid frame for the parasite that helps distance it from its longstanding position as a form of pejorative dehumanization and invasive body horror. Additionally, Chun's work on software usage will provide an avenue to connect the psychoactive worms featured within both texts out to the larger, more subtly systemic control networks of contemporary society. The first of the two selected texts that will be analyzed is Upstream Color, which will then be followed by a similar, yet slightly shorter close examination of INSIDE. These two sections will work to describe the narratives of both texts, specifically focusing on the areas that are most relevant to this paper's theme of parasitism. Finally the paper will conclude by working to present the parasite as a useful tool for artists working within the genre of science fiction who want to investigate the potential 
relationships between free will, anthropocentrism, industrialization, hegemony, and dystopian scenarios. 4

\section{Assemblages and Life Cycles within Upstream Colour}

Upstream Color is an American science fiction film that premiered at the 2013 Sundance Film Festival and had an international theatrical release later that same year. It stars Amy Seitz and Shane Carruth, who also acted as the projects' writer, director, and composer. Within the film Carruth tells a loose narrative of a woman named Kris who falls victim to a traumatic form of mind control without realizing it, and who then later becomes involved in a romantic relationship with a man who experienced the same thing. The film begins with a third character who is referred to in the credits simply as the "Thief". In this opening scene the Thief is shown within what looks like a suburban backyard garden, sifting through the soil of a series of potted blue orchid plants. Eventually through his sifting the Thief finds what he is looking for, a collection of brownish white, grublike worms. The Thief then takes these worms into a nearby house where he strains them through liquid before carefully placing them (still alive) into small red and white pill capsules.

From here the scene shifts to dimly lit, busy night club where Kris is shown drinking and happily speaking with another man. The Thief is seen watching her from another part of the bar and when Kris is not looking manages to stealthily slip one of his worm pills into her drink. As the scene progresses Kris finishes her corrupted drink and becomes visibly unwell, eventually disengaging from her conversation and moving to leave the club. As she steps out into the rainy street she stumbles at which point the Thief quickly advances and places a respiratory pump filled with water and a single living worm over her mouth. The camera cuts to a close-up shot of Kris's distressed face as the worm is pumped from the respiratory apparatus into her body. After a couple seconds Kris coughs up the water and picks herself up from the pavement, now obviously confused and seemingly unaware of the nearby Thief. She walks to her car with the Thief

4 For more on science fiction portrayals of utopia and dystopia within the age of globalization, see Jameson. 
following closely behind where they both get in and drive back to her home where Kris is shown falling asleep.

The next morning Kris, now in a fully hypnotic state, is shown signing a series of cheques and documents that the Thief is presenting to her. The Thief then has her dress in formal business attire and drive him to her bank where she proceeds to transfer all of the money in her savings account over to him. The Thief then has Kris drive them back to her home where he begins to give her a set of complicated instructions to transcribe the entirety of Henry David-Thoreau's 1854 novel Walden while also rhythmically performing busy work such as knitting, paper craft, and object sorting. During the first part of this prescribed busy work the Thief is seen investigating Kris's home, however he eventually exits the scene leaving Kris to continue hypnotically completing the Walden transcription for another full day without stopping to eat or use the washroom. When Kris finally finishes her hypnotically assigned tasks, she rushes to her fridge and messily gorges herself on its contents before passing out in her bed. When she wakes, Kris looks at her legs and becomes aware of the tendrils of the worm moving underneath the skin of her thighs and calves. Now fully aware, she becomes intensely distressed at the realization that she has become infected by another organism and violently tries to dig out the worm with a kitchen knife before falling over and once again losing consciousness.

From here, Upstream Color shifts focus to a new character who, like the Thief, is only referred to in abstraction within the credits as the "Sampler." In this scene the Sampler is shown unloading massive speakers from a white van out in a rural field. He then places the speakers such that the sound will be projected into the ground before returning to the van, loading a cassette tape into a tape deck and boosting the volume. The Sampler then returns to the field where he sets up a lawn chair and a small digital camera on a tripod before sitting down. The scene shifts from day to night and Kris is seen emerging out of the darkness into the lit area around the Sampler's speakers. This seemingly random summoning of Kris to the Sampler is meant as a reference to a practice known 'worm grunting' where you use a metal rod to create sounds and vibrations within the ground that drives all nearby earthworms to the surface. In this case the Sampler is somehow aware 
of the existence of the Thief's worm infected victims and is using the speakers to draw them to him. As Kris approaches the speakers, the Sampler guides her into his van where he has medical equipment and two tables arranged inside. He then has Kris lie down on one the tables and lays an unconscious pig on the other. The scene then briefly jumps ahead in time showing how the Sampler has connected Kris to a machine that draws the worm from her body and then feeds it into the body of the pig.

Although this may seem at first to be a benevolent act, with the Sampler removing the parasitic creature from Kris's body, as the movie progress it is slowly revealed that the Sampler's goals are just as self-motivated as the Thief's. Kris wakes up in her home after the Sampler's deworming surgery with no memory of the event or of the Thief abducting and robbing her. Confused she must now go about trying to recuperate from the time and actions that she cannot recount. As the film switches perspectives from her back to the Sampler, the newly infected pig is shown in a farm paddock with a large group of other presumably infected animals. As the movie progresses the Sampler is depicted making field recordings of the infected pigs on a cassette player, implying that the abstract sounds he used to lure Kris to his van originated from the sounds in and around his farm.

In another key scene the Sampler is shown gathering the offspring of the infected pigs into a cloth bag and drowning them in a nearby river. As the piglet's bodies decompose they release a cloudy blue substance that flows downstream and is absorbed into the root system of a collection of orchid plants that are growing along the shore. These orchids are then gathered up by workers and brought back to the Thief, creating a looped cycle between him, the flowers, the worms, his host victims, the pigs, the Sampler, and the river. Once the process of this strange system is shown, the film cuts back to Kris who suddenly becomes tremendously confused and upset. This sudden change is meant to imply that she still retains some sort of psychic connection to not only the pig in which her parasite was transferred to, but also that pig's offspring. 
Throughout this interconnected web of animals, humans, plants, and their environments, there are many instances of parasitism at work: the Thief relies on the Sampler to grow his worm; the Thief uses the worms to feed off of his victim's wealth; the worm infects the bodies of their hosts; the Sampler uses the Thief's victims to populate his farm; the Sampler relies on the pigs and the environment around his farm produce his field recordings; and finally both the pigs and the Thief's victims partially rely on the Sampler for their health. In her treatise on social parasitism, Watkins Fisher encapsulates this last point especially by stating that

... to be a parasite ... is to be made a stranger in one's own home, as the host that presents itself as welcoming is shown to be capable of administering rent. To be a parasite is to find oneself held hostage to another's imposed hospitality. The rhetoric of parasitism, then, has served to install a ... framework of hospitality through the backdoor (392).

Kris did not ask to have the parasite removed from her by the Sampler in such a way and now she and her pig kin are held hostage to his inexplicable whims. Although she wanted the worm out of her body, she is now subject to a confusing psychic connection with a farm animal and its progeny. And although the pigs rely on the Sampler for food, shelter, and protection they must also contend with his forceful parasitic infections and the systematic execution of their piglets. Both Kris and the pigs have been made strangers in their own homes through the symbiotic actions of the Thief and the Sampler.

In a panel discussion to promote the film, a member of the audience asked Carruth why he chose to so heavily focus on pigs. He replied by talking about the many physiological similarities between pigs and humans and that because of these it would be easier for the audience to believe that a parasite could be passed between them (Wickman). This concept of transference is not only applied biologically as the worm passes from human to pig host, but is also communicated through the psychic connection that is then formed between the two. By the end of the film Kris becomes aware of the existence of the Sampler 
and kills him with a gun. Following this violent encounter Kris then drives out to the Sampler's farm and proceeds to lovingly care for the pigs. Here is she shown as being genuinely happy as she repaints the pig's paddock and feeds them, no longer confused by a psychic connection that she could not explain or recall forming. With this newfound kinship, created through a strange form of cyclical parasitism, Upstream Colour presents a possible utility for the parasite. In her theorizing of the anthropocene, Donna Haraway states that organisms such as parasites, bacteria, and fungus

...give us metaphors; but, metaphors aside...we have a mammalian job to do, with our biotic and abiotic sym-poietic collaborators, co-laborers. We need to make kin sym-chthonically, sym-poetically. Who and whatever we are, we need to make-with-become-with, compose-with-the earth-bound...I think that the stretch and recomposition of kin are allowed by the fact that all earthlings are kin in the deepest sense, and it is past time to practice better care of kinds-asassemblages (161-162).

With its narrative of the worm-pig-orchid life cycle, Upstream Color presents the kind of earthbound assemblage that Haraway is describing, and within its conclusion creates a space for parasitic-mammalian symbiosis through Kris's reconnection with her infected pig at the Sampler's farm5. In this way Upstream Color effectively uses the form and rhetoric of the parasite to deliver something beyond fear or dehumanization that poetically asks audiences to reflect on their relationship to nature and the unseen forces that might guiding their everyday actions. In the next section focusing on INSIDE this last element of control will be more deeply explored through a similar assemblage of humans, pigs, parasites, and other unknown, seemingly omnipotent forces.

\footnotetext{
5 For another example of assemblage theory being applied to a dystopian work of science fiction, see Kunzelman 2018.
} 


\section{Users and Control within INSIDE}

INSIDE is a Danish puzzle-platformer videogame that was initially released for Microsoft Windows and the Xbox One in 2016, then later on for the Playstation 4, iOS, and the Nintendo Switch. The game is constructed using three-dimensional polygonal animation, but players can only move from left to right, with the option of jumping up and down across the screen, rather than exploring any deeper into the backgrounds of the game's depicted scenery. Visually INSIDE has been created using an extremely muted, grey-infused color palette that emphasizes the dystopian themes that is presenting within its narrative, which significantly should be noted is told entirely without dialogue or text.

The game begins at night with a small boy dressed in black pants and a red sweater stumbled down a rocky hill in a dense early autumn forest. As the player moves the boy further through the woods, they see various instances of strangely docile appearing people being lined up and loaded into the backs of trucks by groups of armed guards. If the player is not careful as they move through the trees and one of these guards sees the boy, they will quickly begin to fire or chase the player down and violently choke them. Once the player manages to progress through the forest-all the while witnessing additional scenes of entranced humans being herded like cattle by the malevolent guards-they reach an open field just as dawn begins to break, highlighting a nearby farm that is partially covered by morning fog. As the player moves closer to the farm, the wet grey landscape becomes gradually littered with an increasing number of pig corpses. In one instance the player must swim in a stream to avoid being seen by guards on a bridge above, and the water and shore are completely filled with the dead animals. Here, if the player is observant, they will notice that many of these corpses have long, white wriggling worms emerging from their decomposing flesh. At this point it could easily be presumed that these are meant to be as stylized form of maggot, drawn to the rotting meat of the piled pig bodies, but this will soon be proven not to be the case.

As the player sneaks further into the farm and finds a way into one of its many barns they encounter a lone pig that is still alive. This gaunt, sickly looking pig has one of the worms wriggling out of its backside and will wildly attempt to 
gore and trample the player once they have been seen. To get past this creature the player must trick the pig into ramming through a nearby locked door and smashing its head into a wall on the other side. Once this has been done the player can pull the parasite from the stunned pig's body which causes the animal to seize violently before coming to rest in a docile and deadened state. The player can now use the catatonic pig as a mobile platform tool by pushing and pulling it around the level which then allows the player to gain access to a glowing machine hanging from a long wire connected the ceiling of the barn. The machine resembles the electrode helmet found in early electric chairs and, when interacted with, gives the player control of a human figure in the background who until that point looked to be in a comatose state similar to both the people observed in the forest and recently dewormed pig.

Throughout the rest of the game the player will be tasked with using these mind control devices to get different assortments of drone people to unlock doors, move objects, and in general manipulate the player's environment to allow for them to make forward progress. As the player exits the grey, corpse filled farm they transition into a more urban environment where many more of the human drones can be seen being herded around or performing manual labour. However, despite this enslaved workforce, the concrete-heavy, brutalist city that the player enters into is notably dilapidated with broken signage, flooding, and other similar forms of disrepair presented to the player as puzzles that must be solved. Deeper inside the city, as the player's path takes the boy underground, this dystopian element is even further emphasized as they travel through subterranean, waterlogged offices and laboratories filled with drowned dead bodies and hastily abandoned equipment, implying that whatever disaster struck this world that it happened quite quickly.

As the player reemerges out from the lower flooded areas that constitute the midsection of the game, they begin to see the drone people again. However, there is a startling difference between the relatively normal looking, fully clothed drones seen in the early game and these new variants. The drones that boy must now take control of in order to solve puzzles and make progress are naked and 
deformed, often with missing heads and extra limbs. Additionally, the player encounters strange lab areas where these mutated drone people can be observed suspended pools of gravity defying water above the boy's head. These floating drones, like the decomposing pig corpses floating in the stream at the beginning of the game, are riddled with white worms wriggling out from their bodies.

Finally, as the player reaches the end of the mutant drone-filled labs, they start to see scientists and office workers all running in the same direction. Typically, the boy has had to stealthily avoid these kinds of people throughout the game as if seen they would either attack the boy or called armed guards to shoot him. In this instance however, they see the boy but are too preoccupied to doing anything about him and just continue in their hasty movement towards the right of the screen. As this is the only direction available to the player, eventually they too must follow the along with flow of running people. Eventually the player sees a crowd of the scientists and office workers all crowded around a massive spherical machine. Upon closer observation it can be seen that there are glass windows into the device that all of these people are crowding one another to get a closer look through. The game's camera angle intentionally obscures the contents of the sphere to the player and in order to get a better look they must climb up the through the ceiling rafters of the industrial lab space. Above the giant machine, as the boy is exploring looking for a better vantage point, they are suddenly sucked into a tube that feeds into the sphere. Inside, suspended in water like the mutated drones seen earlier, is an enormous blob of limbs and flesh that is connected to wired devices that look like much larger versions of the helmets the boy has been using to control the drones all throughout the rest of the game. One the boy disconnects each of the wires holding the blob in place it sucks him into its fleshy mass and after a moment the player realizes that they are now in control of the gargantuan creature. From here the player violently breaks out of the spherical machine and crashes through doors and walls at a breakneck pace, smashing equipment and people alike in their clumsy attempt to exit the lab. Eventually, the blob of conjoined drones that the player is now in control of breaks through one final wall and is suddenly outside of urban space that the game has focused on since the player left the cornfields of the pig farm. 
From here the blob falls down a steep, almost cliff-life hill before rolling to an ocean shore below and coming to rest within a small circle of sunlight. The blob is no longer able to be controlled and can assumed to have died from the fall. This is where the game ends.

There are a number of interpretations for this ending, two of the most interesting of which are influenced by a couple important details that many players might miss. The most common interpretation for the ending is that the boy helped the blob escape from its tank and that even if it died it was still able to feel a sense of freedom in its final moments. This interpretation is quickly complicated by the fact that as the blob is hastily escaping through the labs it stumbles past a diorama that looks exactly like its final resting place on the shore, implying that the seemingly unexpected escape sequence is part a more grandly scaled experiment. This interpretation is also supported by the fact that in the blob's efforts to escape, occasionally some of the scientists will open a door for the blob to allow it get through more quickly. The second of the two interpretations is reliant on the player finding and destroying a series of very well hidden miniature versions of the blob's spherical machine as they progress through the game. If the player does this and then goes back to a secret area below the farm at the beginning of the game they will gain access to an alternative ending that gives the standard ending a bit of new context. Here the player will find a dark room with a collection of desktop computers hooked up to the now familiar mind control devices. The only way that the player can interact with anything in this room to unplug the computers, however as soon they do so the boy immediately slumps over and become inert just like the infected pig and the drone people. Together with the blob and how it was connected within its tank to similar mind control devices, this alternative ending implies that boy was never actually the entity that the player was embodying and that they were remotely playing as the boy through the will of blob the entire time (Franklin "Inside (Spoilers)"; "Inside (Addendum) (All the Spoilers)").

Regardless of how either of these endings are interpreted, what is definitively clear is that control functions as both a narrative theme and game 
mechanic within INSIDE. To progress through the game the player must take control of a boy who then uses the technology of a tyrannical government to take control of human drones. These drones have had their free will taken from them through a parasitic infection that is beyond their control. Finally, there is a strong but incredibly ambiguous relationship of control between the boy and the blob that is further complicated by the laboratory they encounter each other within. In this muddy network of control, at times it is not exactly clear who is using whom and for what goal. Wendy Hui Kyong Chun speaks to this confusing web of control within the context of the Internet, a real-world technology that in some ways reflects the networks of machine and minds depicted in INSIDE. Here she states:

Users are used as they use...To claim that users are an effect of software is not to claim that users, through their actions, have no effect. Everyone uses: some use as they are used by fiber-optic networks; some have no access to them and yet are still affected by them. The fact that using makes us vulnerable does not condemn the Internet, for what form of agency does not require risk? (30).

Chun's notion here that use begets more use applies directly to how the boy must use the drones in order for the player to make progress. In this context, although parasitism is most obviously seen within the worm-infested bodies of the pigs and the drones, it also functions as a tool for the boy to make subversive use of the same systems that are being used to take control of his world.

Watkins Fisher describes a similar real-world process in how social media can be used for non-commercialized, activist purposes such as was the case in Arab Spring protest and the Occupy Movement. Here she proclaims: "Parasitism, then, is an anti-strategy for using the conditions by which one is used, performing back the very thing that one is already given to be" (394). Within the grey, broken world of INSIDE parasitism is a strategy and rhetoric that appears to be required if one wishes to remain in control of one's destiny. However, even then, as Fisher and Chun make clear, the distinction between user and used is not a simple one to make. In this way INSIDE complicates any simple or reductive notions around 
parasitism, forcing audiences to consider what entities or technologies they might be using to achieve their goals and how this usage might connect out into broader networks, digital or otherwise.

Although Upstream Color and INSIDE both dip slightly into a kind biological, bodily horror with their use of infectious worms, both narratives end up using parasitism more broadly as a kind of allegorical rhetoric in order to discuss themes of control, leverage, and power. In each of these instances a more powerful entity has used a combination of farm animals and parasites in order to construct a system of manipulation and influence in which they place themselves in the centre. Within Upstream Color this is exemplified through the actions of the Thief and the Sampler who represent two ends of artificially engineered ecosystem of human and non-human actors. Then within INSIDE this same rhetoric of parasitism is shown across a slightly more complex network of technology, flesh, and consciousness that even extends out as far as the player operating the game. ${ }^{6}$ Both texts are united in their depictions of how free will functions across these kinds of influential webs and both propose an alternate route through the controlling influences of these tendrils by going deeper towards their source rather than attempting to escape, hide, or flee.7 As Haraway proclaimed, in the current era of the Anthropocene it is advisable to make kin with the parasites of the world rather than battle or destroy them. Kris completed this kind of parasitic synthesis when she reconnected with her infected pig, and the boy from INSIDE did this at the end of the game when he free and became fused with the blob. Additionally, as Chun stated, in our vastly network world of information it is impossible not to be used or controlled in some way as you navigate the internet. But by choosing to educate yourself and properly protect your information you can at least become aware of how you are being leveraged. When Kris finally become aware of the Thief's and the Sampler's symbiotic cycle she was able to remove herself from it then re-enter as she desired, by killing the Sampler and taking control of his farm. Within INSIDE if the player is curious

\footnotetext{
${ }^{6}$ For more on human and non-human networks of technology, see Galloway; for similar networks within the specific context of videogames, see Kunzelman 2014, and Keogh (especially Chapters 1 and 6).

7 For more on the themes of escape and descent in INSIDE, see Damian Martin.
} 
and explorative enough, they will gain access to new information which will completely recontextualize the ending of the game.

To conclude, both Upstream Color and INSIDE are strong examples of science fiction that work to complicate the ways that the parasite has come to be seen from both a cultural and biological standpoint. Through their collective use of the parasite as a tool that people use to control one another and their environments, both titles speak to the current era in which control seems to falling away on all sides through vastly debated processes such as climate change or the viral spread of radicalized, fascist politics. In this context the parasite might be worth further exploration for artists hoping to subvert these dialogues and systems from the inside, to penetrate into the body of the beast, spread their parasitic tendrils and exert their own form of symbiotic control.

\section{References}

Alien. Directed by Ridley Scott, 2oth Century Fox, May 25, 1979.

Anders, Gullestad M., "Parasite." Political Concepts: A Critical Lexicon, Issue 1, 2000, http://www.politicalconcepts.org/issue1/2012-parasite/.

Burns, Jennifer. Goddess of the Market: Ayn Rand and the American Right. Oxford University Press, Oxford, England, 2009.

Bryman, Alan. The Disneyfication of Society. Sage Publications, London, England, 2004.

Csicsery-Ronay, Istvan. "On the Grotesque in Science Fiction." Science Fiction Studies, Vol. 29, No. 1, 2002: 71-99.

Damian Martin, Gareth. "The Poetics of Progress.” Heterotopias, Vol 1, No 1, 2017: 50-56.

Fisher, Anna Watkins. "User Be Used: Leveraging the Play in the System." Discourse, Volume 36, Number 3, Fall 2014: 383-399.

Galloway, Anne. "Emergent Media Technologies, Speculation, Expectation, and Human/Nonhuman Relations." Journal of Broadcasting \& Electronic Media, Vol 57, No 1, 2013: 53-65,

Haraway, Donna. “Anthropocene, Capitalocene, Plantationocene, Chthulucene: Making Kin” Environmental Humanities, vol. 6, 2015: 159-165. 
Heumann, Joseph and Robin Murray. "Parasite Evolution in the Eco-horror Film: When the Host Becomes the Monster." Monstrous Nature: Environment and Horror on the Big Screen, University of Nebraska Press, 2016: 125-142.

Hui Kyong Chun, Wendy. Control and Freedom: Power and Paranoia in the Age of Fiber Optics. MIT Press, Cambridge, Massachusetts. 2006.

Hurley, Kelly. "Reading Like an Alien: Posthuman Identity in Ridley Scott's Alien and David Cronenberg's Rabid.” Posthuman Bodies. Edited by Judith M. Halberstam and Ira Livingston Indiana University Press, 1995: 203-224.

INSIDE. Direct by Arnt Jensen, Playdead, June 29, 2016.

"Inside (Addendum) (All The Spoilers)" YouTube, uploaded by Chris Franklin, 13 February 2017, https://www.youtube.com/watch?v=qIqxguPvI5Q

"Inside (Spoilers)" YouTube, uploaded by Chris Franklin, 29 January 2017, https://www.youtube.com/watch?v=ln6WUbIXTIs

Jameson, Fredric. Archaeologies of the Future: The Desire Called Utopia and Other Science Fictions. Verso, New York City, New York, 2017.

Keogh, Brendan. A Play Across Bodies: How We Perceive Videogames. MIT Press, Cambridge, Massachusetts. 2018.

Kunzelman, Cameron, "The Nonhuman Lives of Videogames.” Thesis, Georgia State University, 2014. https://scholarworks.gsu.edu/communication_theses/110

Kunzelman, Cameron. "Videogames, Assemblages, Rot." Beyond the Seas: Navigating Bioshock. Edited by Jessica Aldred and Felan Parker, McGillQueen's University Press, Montreal \& Kingston, Canada, 2018.

Lathham, Robert, editor. Science Fiction Criticism: An Anthology of Essential Writings. Bloomsbury Academic, London, England, 2017.

Monsters Inside Me. Directed by Kyle McCabe, Alexis Siggers, Sally Freeman, and Ed Hambleton, Animal Planet and the Discovery Channel, July 12009 - December 17, 2017.

Prometheus. Directed by Ridley Scott, 2oth Century Fox, April 11, 2012.

Slither. Direct by James Gunn, March 31, 2006. 
Shivers. Directed by David Cronenberg, October 10, 1975.

The Faculty. Robert Rodriguez, Miramax Films, December 25, 1998.

The Thing. Directed by John Carpenter, June 25, 1982.

Upstream Color. Directed by Shane Carruth, VHX, January 21, 2013. https://slate.com/culture/2013/o4/upstream-color-faq-analysis-and-themeaning-of-shane-carruths-film.html

Wickman, Forrest. "FAQ: Upstream Color." Slate, April o9, 2013. ilm.html 